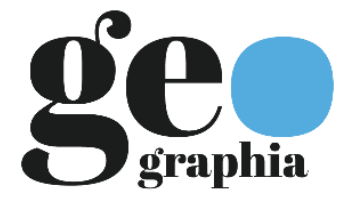

\title{
ARTIGOS
}

\section{LUGAR E ESPAÇO PÚBLICO: A PRESENÇA DA DIFERENÇA EM BATALHAS DE MC EM BELÉM, PARÁ}

Eryck de Jesus Furtado Batalha ${ }^{1}$

Universidade Federal do Pará

Enviado em 17 jul. 2019 | Aceito em 29 mai. 2021

Resumo: Este artigo tem como objetivo estudar a relação entre lugar e espaço público no contexto da realização de Batalhas de MC em praças de Belém, Pará. Justificamos a realização deste trabalho pela necessidade de compreendermos as ações do movimento hip hop a partir das particularidades dos seus sujeitos, aqui analisadas com base nas suas diferenças, portadoras de identidades espaciais afetivas: seus lugares. A complexidade espacial das periferias de Belém sugere que as demandas que surgem das vivências desses sujeitos contêm riquíssimas informações acerca da potencialidade política desses encontros. Foi realizado um levantamento bibliográfico acerca do tema, com o objetivo de obter um panorama do campo de estudos, assim como trabalhos de campo de cunho etnográfico, o que permitiu perceber que o lugar possui destacada importância na realização destes eventos no espaço público, por serem fonte das particularidades que permitirão o encontro de diferenças no espaço, promovendo ações políticas que o definem e reafirmando suas próprias existências. Palavras-Chave: Lugar; Espaço Público; Batalhas de MC.

\section{PLACE AND PUBLIC SPACE: THE PRESENCE OF DIFFERENCE IN MC BATTLES IN BELÉM, PARÁ}

Abstract: This article aims to study the relationship between place and public space in the context of the performance of MC Battles on the streets of Belém, Pará. The accomplishment of this work is justified by the need to understand the actions of the hip hop movement from the particularities of their subjects, in this piece analyzed based on their differences, carrying spacial affective identities: their places. Belém periphery spatial complexity suggests that the demands that arise from the experiences of these subjects hold informations about the political potential of these meetings. Bibliographic survey was carried out about the topic in order to obtain an overview of the field of study and field of ethnographic nature, which allowed us to realize that the place has highlighted importance on achievement of these events in the public space, because they are source of the particularities which allow the differences in space, promoting political actions that defines them and reaffirming their own existance.

Keywords: Place; Public Space; MC battles.

\section{LUGAR Y ESPACIO PÚBLICO: LA PRESENCIA DE LA DIFERENCIA EN LAS BATALLAS DE MC EN BELÉM, PARÁ}

Resumen: Este artículo tiene como objetivo estudiar la relación entre lugar y espacio público en el contexto de Batallas de MCs en plazas de Belém, Pará. Justificamos este trabajo por la necesidad de comprender las acciones del movimiento hip hop desde las particularidades de sus sujetos, aquí analizados a partir de sus diferencias, portadoras de identidades espaciales afectivas: sus lugares. La complejidad espacial de las periferias de Belém sugiere que las demandas que surgen de las experiencias de estos sujetos contienen información muy rica sobre el potencial político de estos encuentros. Se realizó un levantamiento bibliográfico sobre el tema, con el objetivo de obtener una visión general del campo de estudio, así como un trabajo de campo de carácter etnográfico, que permitió darnos cuenta que el lugar tiene una importancia destacada en la realización de estos eventos en el espacio público, pues son fuente de las particularidades que permitirán el encuentro de diferencias en el espacio, impulsando acciones políticas que los definan y reafirmando su propia existencia. Palabras clave: Lugar; Espacio Público; Batallas de MC.

1. Doutorando em Desenvolvimento Sustentável do Trópico Úmido no Núcleo de Altos Estudos Amazônicos (NAEA) da Universidade Federal do Pará (UFPA). Mestre em Planejamento do Desenvolvimento. ORCID: https://orcid.org/0000-00025224-0220. E-mail: eryck_batalha@hotmail.com. 


\section{Introdução}

Este artigo possui como tema a relação entre espaço público e lugar, tendo como recorte empírico as batalhas de rap que ocorrem em praças da cidade de Belém, Pará. Com o intuito de compreendermos a importância dos lugares no contexto da realização de encontros promovidos pela cultura hip hop, buscamos nos debruçar sobre a natureza desses eventos nos espaços públicos da cidade.

O conceito de espaço público é considerado aqui enquanto um trunfo nas análises acerca das grandes cidades. Alguns autores, como Leite (2004), Serpa (2007) e Gomes (2014) indicam a possibilidade de compreendê-lo enquanto um espaço capaz de comportar as diferenças que compõem a totalidade da cidade, os grupos que fazem parte do mundo urbano e que carregam consigo as particularidades que vão diferenciá-los.

O movimento hip hop, hoje, está em vários lugares no mundo, incorporando, nas periferias onde é recebido pelos jovens, premissas locais e globais em realidades distintas, mas que partilham características que as aproximam, como a pobreza, violência e discriminação, agregando demandas que representam países, cidades, bairros e comunidades. Esse caráter local-global que o movimento assume permite que uma linguagem, reconhecível através do estilo partilhado dentre os jovens protagonistas do hip hop, seja utilizada para a manifestação dos diferentes discursos que estes carregam.

A produção do movimento é reflexo das condições socioespaciais em que esses sujeitos estão inseridos. O cotidiano, as lutas coletivas e o anseio por melhores condições de vida são a base de suas ações dentro do hip hop. Partilham uma linguagem característica de expressões culturais que se mesclam com a política e vice-versa, que, somando-se aos temas relacionados com o aprendizado sobre suas realidades, histórias pessoais, acontecimentos históricos e o próprio folclore da região, compõem o interesse dos participantes que constroem o movimento em Belém.

O hip hop é geralmente compreendido através de sua divisão em três dimensões e quatro elementos. As dimensões são formas de organização que aglutinam preferências artísticas e os elementos são as pessoas que dão vida a elas, realizando as atividades relacionadas às mesmas. A dimensão musical, o rap, engloba o elemento DJ, responsável pela mixagem e controle do som, e o elemento MC, que vai animar a "galera" e rimar com base nas batidas. A dimensão gráfica, o grafite, é composta pelos elementos grafiteiro ou grafiteira, elementos responsáveis pela impressão física dos discursos do movimento na cidade. A dimensão da dança, o break, engloba os elementos B. Boy e B. Girl, responsáveis pela tradução, no corpo, do hip hop.

O rap nos oferece parâmetros para pensar o hip hop a partir de sua produção textual, nas músicas e rimas, assim como nos discursos apresentados por esta mesma produção. Os textos que surgem das vivências dos protagonistas do movimento e participantes do mesmo representam uma visão dos seus lugares, demandas e denúncias expressas nos encontros e socializadas em uma dinâmica de troca de experiências e exposição mútua dentre os participantes.

As batalhas de rap são o tipo de evento que, de forma mais incisiva, ocupa, mesmo que de maneira temporária, os espaços públicos da cidade, portanto será nele que concentraremos nossos esforços analíticos, tendo como sujeitos desta pesquisa os rappers, MC, DJ e participantes "ouvintes" dos eventos, jovens que levam suas particularidades, seus corpos, objetividades e subjetividades para os espaços da cidade.

Precisamos entender que estes grupos constroem relações identitárias entre si e com seus lugares, de modo a estarem intrinsicamente ligados a realidades locais, que carregam dificuldades, 
demandas e lutas comuns aos seus iguais. Essas particularidades poderão ser explicitadas de forma contundente somente através do encontro com o outro, o diferente. Esse encontro poderá ser realizado, no entanto, apenas em um espaço que possibilite a coexistência dessas diferenças, não necessariamente de forma harmônica, mas sem a disputa desse mesmo espaço pelos grupos que ali se encontram. Deverá ser um espaço de intersecção.

Justificamos a realização deste trabalho pela necessidade de compreendermos as ações do movimento hip hop a partir das particularidades dos seus sujeitos, aqui analisadas com base nas suas diferenças, portadoras de identidades espaciais afetivas, seus lugares. A complexidade espacial das periferias de Belém sugere que as demandas que surgem das vivências desses sujeitos serão portadoras de riquíssimas informações acerca da potencialidade política desses encontros.

Para a realização deste trabalho utilizamos uma perspectiva qualitativa, de caráter emergente (CRESWELL, 2007), de modo que os procedimentos não foram imutáveis ao longo do seu desenvolvimento, se adequando às necessidades apresentadas pelo campo em um processo de troca constante entre pesquisador e objeto.

Nosso posicionamento enquanto pesquisador foi definido a partir da vivência que possuíamos junto ao grupo estudado. Gold (1958) apresenta uma análise sobre os papéis que os pesquisadores em ciências sociais geralmente assumem perante o campo e as limitações de cada um desses papéis nas relações estabelecidas entre o pesquisador, consigo e/ou com seu informante em campo. O Participante como Observador, posição na qual nos encaixamos, assume uma postura em que tanto o pesquisador quanto os sujeitos pesquisados estão cientes de que a relação estabelecida entre eles é uma relação de campo de pesquisa, segundo Gold (1958). Nesse caso, as relações de desconfiança entre pesquisador e informante tendem a se apaziguar à medida que ambas as partes se conhecem melhor e desenvolvem confiança.

Com base no grupo estudado e nos dados necessários para responder às questões estabelecidas, optamos pela utilização da etnografia urbana como método para guiar nossa observação em campo. A utilização da etnografia aqui, portanto, nos guiou durante os trabalhos de campo e recolhimento de dados. Segundo Velho (1980), a possibilidade de partilharmos patrimônios culturais com outros sujeitos de nossa sociedade não deve nos iludir a respeito das descontinuidades e diferenças provindas de trajetórias, experiências e vivências específicas (VELHO, 1980).

Magnani (2002), por sua vez, em um texto sobre propostas para uma etnografia urbana, destaca que o lugar comum das análises dos processos urbanos tem como característica a ausência de atores sociais, ou ao menos de certos atores sociais. Trata-se da invisibilidade de grupos que não fazem parte dos representantes do capital, ou agentes clássicos da produção do espaço em uma perspectiva macro que envolve os grandes processos que moldam a cidade. A proposição do autor, de uma etnografia "de perto e de dentro", tem como objetivo se aproximar de um urbanismo socialmente includente que consiga enxergar grupos e práticas que geralmente são ocultados. Assim, o autor propõe o resgate de um olhar próximo e participante capaz de identificar, descrever e refletir sobre os aspectos negligenciados na perspectiva daqueles enfoques que ele qualifica como "de fora e de longe" (MAGNANI, 2002).

A pesquisa de campo nessa orientação, portanto, busca compreender os significados que os sujeitos atribuem às suas ações, levando o pesquisador a imergir no seu mundo e despir-se de uma condição neutra. Os meios de contato foram as batalhas de rap, em conversas marcadas individualmente e através de meios digitais. 


\section{Lugar e espaço público: diferenças no/do urbano}

A discussão acerca do lugar - conceito que foi, de forma mais forte, abraçado por vertentes da geografia a partir da década de 70 - é complexa e chega mesmo a dividir opiniões no interior da ciência. Aqui consideramos, no entanto, o lugar enquanto "um espaço percebido e vivido, dotado de significado, e com base no qual desenvolvem-se e extraem-se os "sentidos de lugar" e as "imagens de lugar" (SOUZA, 2013, p. 114). Neste artigo utilizamos Leite (2004) para compreendermos a natureza das relações estabelecidas entre o lugar e o espaço público, de modo a observarmos as mesmas na cidade de Belém.

Por lugar, o autor compreende "uma determinada demarcação física e/ou simbólica no espaço, cujos usos o qualificam e lhe atribuem sentidos diferenciados, orientando ações sociais e sendo por estas delimitado reflexivamente" (LEITE, 2004, p. 284). O lugar, portanto, será sempre um espaço dotado de sentidos advindos das relações que ocorrem nele. Essas relações, no entanto, são aquelas que possuem sentidos que convergem para que se criem identidades afetivas heterogêneas que consigam estabelecer sentidos no espaço. "A convergência de sentidos atribuídos é, portanto, uma condição necessária para que se pratique um espaço e o transforme em lugar (LEITE, 2004, p. 284).

O lugar, é necessário dizer, vai assumir um caráter subjetivo a partir dos sentidos que lhe são atribuídos, não existindo, portanto, apenas um sentido de lugar. Segundo Massey (1994) a inserção social das pessoas no espaço ocorre de forma diferenciada, de modo que os sentidos de lugar serão, também, diferentes, conferindo ao lugar uma natureza fluxa.

Segundo Leite,

os lugares urbanos têm fronteiras, mas elas não são necessariamente fixas e muito menos dadas: são construídas socialmente e negociadas cotidianamente com outros lugares no complexo processo de interação pública, através do qual afirmam suas singularidades, emergem conflitos, dissenções e, eventualmente, consensos. A convergência de sentidos é assim, condição necessária para que se "pratique" um espaço e o transforme em lugar, e não implica, necessariamente, consenso, mas possibilidade de entendimento (LEITE, 2004, p. 286).

Essas práticas de negociação entre lugares só serão possíveis a partir do encontro entre os mesmos. Para que um lugar possa existir a partir de suas diferenças ele necessita ter contato com outros, de modo a se afirmar nas suas singularidades. Concordamos com LEITE (2004, p. 298) quando ele diz que "um lugar é sempre um espaço da construção da diferença". Essas diferenças irão se reafirmar e dialogar entre si, portanto, no espaço público.

Ângelo Serpa define o espaço público enquanto "o espaço da ação política, ou, ao menos, da possibilidade da ação política na contemporaneidade" (SERPA, 2007, p. 9). Essa ação política será a ação das diferenças, que se encontram, dialogam e, em suas tensões, promovem a igualdade. Se trata, também, de um "espaço simbólico, da reprodução de diferentes ideias de cultura, da intersubjetividade que relaciona sujeitos e percepções na produção e reprodução dos espaços banais e cotidianos" (SERPA, 2007, p. 9).

O espaço público será considerado aqui, portanto, enquanto o espaço das diferenças, que vai oferecer as condições necessárias para que indivíduos ou grupos possam exercer suas diferenças entre si, se pondo diante do "outro" e, a partir dessa relação, explicitando as particularidades uns dos outros (LEITE, 2004, p. 313).

Serpa (2007), através da leitura de Cosgrove (1998), ressalta que uma das barreiras para que isso aconteça de forma plena nos espaços das cidades é o fato de que existem culturas dominantes e subdominantes que expressam poder através de sua autorreprodução. Seria necessário, portanto, 
uma "construção de processos identitários que não procedam à reificação da cultura popular nem da cultura dominante, para a construção de algo realmente novo" (SERPA, 2007, p. 143). Para o autor, inclusive, a diferença seria o elemento fundante da igualdade, ao invés da identidade, visto que

quando a diferença é o elemento fundante, a realidade é constituída por processos identitários decorrentes da precipitação dos acontecimentos; mas se é a identidade o elemento fundante, a diferença é apenas um "dado da realidade", precipitando acontecimentos sem gerar processos identitários dinâmicos e (sempre) instáveis. (SERPA, 2007, p. 144)

Defende-se aqui a ideia de que, se não há hierarquia, todos os pontos de vista são importantes para a construção de espaços para a expressão dos conflitos e contradições que compõem as diferenças de diversos grupos na cidade (SERPA, 2007).

Compreendemos o espaço público, portanto, enquanto esse espaço em que as diferenças que compõem a cidade podem se expressar de forma igualitária, não necessariamente solidária, mas sempre de forma complementar, em uma relação que envolve o contato de subjetividades e objetividades sempre em movimento, que dependem de uma relação de visibilidade para se afirmarem perante umas às outras. Para que tal relação ocorra de forma plena é necessário que não haja hierarquização de um grupo sobre o outro, de forma hegemônica, possibilitando que as diferentes expressões não precisem disputar espaços, mas que o diálogo entre elas possa ocorrer sem embargos.

Nas palavras de Gomes,

trata-se, portanto, essencialmente de uma área onde se processa a mistura social. Diferentes segmentos, com diferentes expectativas e interesses, nutrem-se da co-presença, ultrapassando suas diversidades concretas e transcendendo o particularismo, em uma prática recorrente da civilidade e do diálogo (GOMES, 2014, p. 163).

Gomes, assim como Serpa (2007) e Leite (2004), entende que a diferença é de suma importância ao tratar desse conceito, primeiramente porque é no espaço público que se exercita a "arte da convivência", o espaço da vida pública. Para Gomes, o substrato físico orienta os comportamentos e práticas nesses espaços, que por sua vez reafirmam o caráter público do mesmo, em uma relação interdependente que dá origem a uma forma-conteúdo responsável pela mediação dessas diferenças, o lugar do conflito (compreendido enquanto o contato não harmônico destas diferenças) e das problematizações referentes às questões ligadas ao cotidiano, assim como às demandas relacionadas ao mesmo (GOMES, 2014).

\section{Hip hop e batalhas de rap em Belém, Pará}

Não possuímos a pretensão de oferecer uma descrição histórica detalhada sobre os eventos cronológicos fundantes do movimento hip hop em Belém/PA, preferindo destacar alguns pontoschave que julgamos importantes para a consolidação do movimento, tal como o conhecemos hoje: amplo em sua heterogeneidade e unificado na construção de uma identidade mobilizadora.

Segundo Silva (2009), a gênese do movimento em Belém está ligada ao bairro da Terra Firme, localizado em uma zona periférica da cidade. O break, elemento ligado à dança, foi o primeiro a ser praticado, ainda no início da década de 90 (BORDA, 2016), mas que, assim como em outros pontos do país, não possuía, nesse momento, a consciência política que iria adquirir mais tarde.

Os B.boys e B.girls se reuniam em espaços da cidade (a praça Floriano Peixoto é indicada, como nos disse uma MC em entrevista realizada em janeiro de 2017, como o solo sagrado do hip hop em 
Belém por conta de ter sido o palco das primeiras manifestações do break) para praticar e exibir seus passos, em disputas que, na maioria das vezes, eram uma atividade de lazer. 0 encontro de pessoas que praticavam essa atividade, com outras, que construíam outras dimensões do movimento, vai alterar essa dinâmica.

Silva (2009) nos diz que a partir da organização de grupos de jovens que consumiam o rap e que possuíam interesse em criar suas próprias composições, relações com o break foram estabelecidas e a ligação destas manifestações do movimento com seus lugares foi o pontapé inicial para a percepção de que se tratava de um movimento cultural e político. Nesse período ainda se sofria com a falta de informações veiculadas na mídia sobre o break ou o rap, que, quando citados, eram esvaziados de seu conteúdo político.

Segundo Silva,

\begin{abstract}
a formação dos grupos de rap cujas letras passavam a retratar a realidade do contexto onde jovens moradores da periferia estavam inseridos deu um grande passo para a legitimação do hip hop, enquanto movimento de origem periférica, bem como para a consolidação do seu território na cidade, a medida que os jovens passaram a divulgar o discurso do hip hop e fazer dele um projeto de atuação política e intervenção artística na paisagem urbana. Deste modo, o movimento vai construindo seus territórios na metrópole, influenciando os modos de ser, resignificando a baixada, tornando-se visível (SILVA, 2009, p. 7).
\end{abstract}

Bruno Borda (2016) fala sobre uma organização, a Nação da Resistência Periférica (NRP) Movimento Hip hop Organizado (MH2O/Pa), enquanto a de maior expressão da cultura hip hop em Belém. Isso porque essa entidade aglutinou aqueles que podem ser considerados "pioneiros" do movimento na cidade.

O autor também revela relações e conflitos que serão importantíssimos para compreendermos o desenvolvimento e nascimento de segmentos do movimento na cidade. Uma delas é a ligação com o Partido dos Trabalhadores (PT) no contexto das eleições para a Prefeitura de Belém, no final dos anos noventa. Ao mesmo tempo, o Mocambo, entidade do movimento negro em Belém, era responsável por aglutinar pessoas envolvidas com o hip hop, estas que, segundo Borda,

\begin{abstract}
foram vitais na consolidação de uma proposta organizatória no hip hop em Belém, como Muslim e Black Z, MC de rap e ativistas do movimento. Porém esta relação foi abalada com o episódio do "Canto a Zumbi", primeiro show de rap em Belém com participação de grupos de São Paulo e do Rio de Janeiro (...) Neste evento promovido no ano de 2000, a NRP em parceria com o Mocambo, trouxe a Belém os MC Xis, Edi Rock (Racionais MCs), Lakers (Código Fatal) e MV Bill, e mais o DJ KL Jay (Racionais MCs), porém o evento infelizmente acabou não gerando o lucro necessário para pagar despesas como as passagens dos artistas, quanto a esta questão os dois movimentos não chegaram a um denominador comum de como quitar a dívida, isto tornou-se o estopim de uma divergência que encontrava raízes em visões diversificadas sobre os rumos e a condução da entidade NRP (BORDA, 2016, p. 25).
\end{abstract}

Mesmo com resultados financeiros negativos, o autor afirma que depois desse episódio as relações da NRP, primeira entidade formada com interesses prioritários associados aos conceitos da cultura hip hop, com outras entidades do movimento negro e com a Prefeitura Municipal, principalmente depois da criação do Conselho Municipal do Negro (CMN), foram alargadas e aprofundadas (BORDA, 2016).

Através das relações com entidades que surgiram a partir da NRP foi possível "a atuação do hip hop junto à juventude da periferia da cidade, por meio de ações mais pontuais, principalmente em bairros como a Guanabara, o Guamá, a Terra Firme e o Jurunas" (BORDA, 2016, p. 25). Também nesse contexto observamos a existência de conflitos, como a crítica realizada ao direcionamento centrista 
do PT, ocasionando a não participação do movimento no último Festival de Cultura de Rua, evento promovido pelo governo municipal que contava com parcerias de organizações hip hop de Belém e "promovia a visibilidade do projeto social da prefeitura chamado "Cores de Belém", que trabalhava a linguagem do grafite com ex-pichadores" (BORDA, 2016, p. 25-26).

A apropriação da cidade enquanto palco e inspiração para estes grupos vão se desenvolver para que o caráter reivindicatório do hip hop seja reconhecido e fortalecido pelo surgimento de eventos, artistas relacionados ao estilo e a divulgação massiva que meios, como a internet, passam a possibilitar. Surge uma cena forte do hip hop em Belém. Antes de prosseguirmos é interessante dizer o que entendemos por cena. Segundo Neto (2008, p. 58-59), se trata do

Estabelecimento de fronteiras identitárias, ligadas a estilos, constituídos de certo tipo de música, visual e comportamento. Essas fronteiras delimitam, além de espaços virtuais, espaços de encontro e manifestação na cidade, que são pontos de conexão, permanentes e/ou temporários, da rede de sociabilidade tramada em torno do estilo. Espaços que resultam de negociação com outros grupos sociais, na cidade, e que dizem muito sobre as possibilidades reais de territorialização dos estilos globais, nos contextos urbanos concretos.

Tais fronteiras identitárias definem um perfil que formará grupos com formas de pensar e agir que, apesar de não padronizadas, se aproximam o suficiente para que se constituam como tal. No hip hop, ao falar de cena nos referimos à capacidade de definir uma identidade e reproduzi-la através de interações e afirmações de práticas espaciais. Algumas características do hip hop em Belém nos permitem concebê-lo em suas formulações gerais, em contato com o hip hop produzido no resto do mundo, assim como nas suas particularidades locais.

Segundo os relatos de Borda (2016) e Silva (2009) podemos perceber que a própria trajetória do hip hop em Belém é marcada por processos conflituosos que vão definir sua atuação. Partindo do respeito às diferenças, umas das principais demandas do movimento, o hip hop vai se descentralizar de organizações fundadoras para se expandir em outras, tão numerosas quanto as demandas que ele incorpora, e apesar de não termos aqui a intenção de enumerá-las reconhecemos que um estudo que se aprofunde detalhadamente na sua história seria bem-vindo.

Os dados apresentados aqui foram obtidos através de pesquisas em campo e conversas com sujeitos que percorrem o circuito de batalhas rotineiramente, assim como organizadores das batalhas, além, é claro, de minha frequência nesses eventos enquanto jurado ou apenas observador, no período entre 2016 e 2019.

Durante os trabalhos de campo direcionados a esta pesquisa visitamos algumas batalhas de rap que ocorrem em Belém com o intuito de conhecer a cena local, vivida por muitos dos jovens que praticam o freestyle nesses eventos.

Perante a impossibilidade de frequentar com o mesmo empenho todas as batalhas que ocorrem na cidade, por conta principalmente da coincidência de dias, horários e do número elevado de locais que precisariam ser visitados semanalmente, ativemo-nos a quatro batalhas: a Batalha de São Brás, a Batalha da Batista, a Batalha do Guamá e a Batalha do Triângulo. Notamos, no entanto, a partir de algumas entrevistas com pessoas que circulam cotidianamente por esses eventos, que poucas são as diferenças de organização e realização dos encontros, que também compartilham boa parte de seus participantes. Iremos descrever as quatro batalhas destacadas com a noção de que elas podem, parcialmente, oferecer um panorama amplo que se estende àquelas não aprofundadas neste trabalho.

A Batalha de São Brás é um evento ligado à cultura hip hop que tem como dimensão principal de atuação o rap, mais especificamente a batalha de rap. Nasce em 2013 por meio da vontade de algumas pessoas atuantes do hip hop belenense, que a partir da necessidade de um ponto de 
encontro para a realização de atividades de lazer escolheram a Praça Floriano Peixoto. A relação do movimento com essa praça vem de longa data, como já citado anteriormente, visto que as primeiras manifestações da cultura hip hop em Belém ocorreram no amplo calçamento referente ao pátio do Mercado de São Brás. A escolha do ambiente também está alicerçada na facilidade de acesso por meio de transporte público e da proximidade com vários bairros de residência da maioria dos participantes, como o bairro do Guamá, Terra Firme, Cremação e Canudos. A presença de pessoas de bairros mais distantes, como Tapanã, Pedreira e Sacramenta também pôde ser notada durante a realização das batalhas por conta do acesso facilitado via transporte público.

A proximidade com bairros periféricos da cidade também pode ser entendida como um fator para que jovens desses bairros prefiram utilizar a praça para suas atividades. Moradores próximos, comerciantes e demais pessoas que transitam pelo local, como se verificou durante nossos trabalhos de campo, não se sentem seguros. O sentimento de insegurança acaba por caracterizar as relações neste espaço na maior parte do tempo, limitando seu uso apenas à necessidade da utilização dos serviços disponíveis ali ou enquanto espaço de circulação.

No momento em que as atividades da Batalha de São Brás passaram a ser realizadas na praça algumas características do espaço foram percebidas pelos organizadores, como nos contou um MC, entrevistado em janeiro de 2017. Em 2013 o estado da praça era de abandono, sendo frequentada apenas por grupos pontuais que realizavam atividades esportivas ou culturais de forma descontínua. Tal abandono estava ligado à falta de manutenção do ambiente no período (apesar da reforma realizada em 2012) e pelo ambiente de insegurança gerado pelo sucateamento do espaço.

A partir do momento do início das atividades da Batalha de São Brás na praça, em 2013, os participantes se resumiam aos organizadores, pessoas próximas aos mesmos e outras ligadas ao movimento e atentas à cena local. Com o tempo a Batalha cresceu, contando com a visibilidade do local escolhido, divulgação massiva em redes sociais e através da crescente visibilidade de seus organizadores na cena local, regional e nacional. No início das atividades os encontros ocorriam nas quintas, dentre 19:30h e 20:30h, no entanto, a partir de pressões da Guarda Civil, foram alterados os horários e atualmente ocorrem a partir de 18h, se estendendo até o horário limite de $21 \mathrm{~h}$, aos sábados.

A Batalha de São Brás se tornou um ponto de encontro importante para a cultura hip hop em Belém, atraindo pessoas tanto da capital quanto de municípios próximos, como Ananindeua, Marituba, Benevides, Dom Eliseu, etc. Picos de 300 a 400 pessoas chegaram a participar do evento em algumas noites, demonstrando a importância que esse evento adquiriu na cena local.

Sobre as mudanças ocorridas na praça Floriano Peixoto a partir da Batalha de São Brás, S. M. J., MC e ativista do movimento, nos diz que

os olhares se voltaram pra São Brás depois que começou a acontecer as Batalhas. Em São Brás, como eu te falei, sempre teve gente lá fazendo as danças deles e tal, se passava no ônibus, olhava aquilo ali e não se via muito entusiasmo. Depois da batalha não, o pessoal já tinha um olhar diferenciado pra lá. Quando se passava ali já sabia que tinha alguma coisa: "ah é a batalha", "ah, é o hip hop". O pessoal começou a entender que tinham outras coisas acontecendo ali. E a Floriano Peixoto passou a ganhar outras formas de expressão também: o pessoal da capoeira, o pessoal da quadrilha junina, que já até começaram a ensaiar. Eles ensaiavam muito lá atrás do Mercado, agora já ensaiam ali pela frente. Começou a ter uns sarais culturais por lá, que inclusive são de companheiros de vários movimentos sociais, de vez em quando eles me chamam pra fazer um sonzinho lá. E São Brás também se transformou de tal forma que você vê que começou a aparecer pessoas pra comercializar lá: um carro de lanche, uma venda aqui, outra ali. Aquilo foi movimentando, gerou renda, né? De certa forma, aquilo que começou como uma proposta pequena, só de uma batalha de uma cultura, ela tomou uma dimensão grande e ela englobou essa questão da renda, né. A cultura em si, num olhar diferenciado pra ali e também um olhar pro Mercado de São Brás, porque se você 
percebeu o Mercado de São Brás ele tá sucateado, aí tem muitos que culpam o hip hop, ah porque tá tudo pichado e "tal's", mas não deixa de ser uma intervenção e lá o próprio Mercado de São Brás, a estrutura dele é uma estrutura bonita, acho que se organizar dá pra fazer muita coisa bonita ali dentro. (Informação verbal) ${ }^{1}$

A dinâmica da praça se altera quando o hip hop se faz presente. O espaço adquire outras relações e outros grupos se sentem atraídos a ocuparem e permanecerem na praça. Essas outras formas de expressão salientadas por nosso interlocutor, como o uso da frente do Mercado para ensaios, ao invés dos fundos, a intensificação da presença do "pessoal da capoeira" na praça, a realização de sarais culturais e, aliado a tudo isso, a atração de comerciantes. Esta última atividade chama a atenção de forma especial por incluir tanto ambulantes que vivem do comércio informal quanto pessoas que compõem o movimento hip hop e complementam a renda nesses momentos com venda de comida, acessórios, bebidas, etc.

Essas mudanças, ainda que à primeira vista limitadas aos dias e horários de evento, causaram um grande impacto na forma como o espaço público em questão é interpretado e utilizado. Quanto à interpretação, esse impacto se baseia na percepção nova que se criou, por meio do uso e das potencialidades percebidas por meio deste. O espaço, que antes era negligenciado e subutilizado pelos grupos citados, agora é palco de manifestações antigas e novas, por meio de sujeitos que o percebem de forma diferente e, portanto, fazem outros usos do mesmo.

A Praça Batista Campos é um espaço ricamente frequentando durante todas as horas do dia, sendo uma das principais opções para quem pretende realizar atividades físicas ou simplesmente passear com segurança. A praça conta com uma guarita da Polícia Civil que funciona durante 24h, garantindo a vigilância sobre os usos do espaço e garantindo a segurança patrimonial nas suas dependências. Aliado a isso, a existência de pontes, bancos, coretos, equipamento de ginástica e outras estruturas convidativas para a permanência fazem da praça Batista Campos uma das mais utilizadas para o lazer em Belém. O entorno se caracteriza por residências de classe alta, lojas, supermercados, lanchonetes, escolas, bancos e órgãos públicos, conformando uma centralidade na oferta de produtos e serviços. A proximidade com um dos shoppings da cidade também garante a intensa circulação de pessoas por ali, que, ao contrário do que ocorre em outras praças estudadas, não se sentem inseguras ou desconfortáveis no local.

A Batalha da Batista Campos ocorre desde 2018 na praça que Ihe batiza. Organizada por um grupo de jovens que já na escola adquiriram interesses relacionados ao hip hop, ela é fruto da vontade de criar um espaço em um local acessível onde eles pudessem rimar. Segundo V. F., um dos organizadores da batalha,

tudo começou ano passado, na escola, tá ligado? Ficava com uns amigos meus e tal, "égua, tu viu aquela batalha e tal, batalha da aldeia, foda e tal, entendeu?", uma batalha que se destacava, aí a gente começou a rimar, tipo na zoeira, tá ligado, a gente chegava na quadra da escola e ficava tentando rimar, tá ligado, essas coisas de quem tava começando, mas ninguém queria nada sério, tá ligado? Naquele tempo era só zoeira. Aí uma vez, era um sábado, tá ligado, aí tinham quatro amigos nossos lá, aí a gente tava começando a rimar, né? Aí a gente rimou aí quando fui ver já tinha uma galera lá em volta, né? (Informação verbal)²

Ele continua, sobre a escolha da praça Batista Campos:

Uma vez a gente tava passeando, mano, aí a gente tava lá na Batista, aí a gente começou a resenha, a gente começou a rimar, perto daquele coreto lá, começar a rimar, e tal, aí foi que em outubro a gente tava começando a rimar, aí já tinham uns amigos meus que estavam colando lá no coreto da batista. (Informação verbal)² 
A importância da influência da Batalha de São Brás nesta narrativa fica explicita quando ele diz que

\begin{abstract}
teve um evento que era o Pelé do Manifesto e o Everton MC, que rolou lá no centur, mano, aí eu fui pra esse evento, aí a gente começou a se empolgar, mano, eu comecei a ficar mais sério, a querer rimar, tá ligado? Aí foi que uma certa vez, numa sexta feira, tá ligado, o Rasta colou lá na Batista, ele e a namorada dele, aí eu fiquei "égua, é o Rasta, esse bicho que vai pra Nacional, tá ligado?", foi antes de rolar a nacional. Aí eu falei pra ele: "mano, tem como tu divulgar a nossa batalha pra gente rimar e tal, pra gente tornar essa parada séria?" Aí foi que ele bateu uma foto com a gente e falou que tinha encontrado um grupo de jovens fazendo freestyle. (Informação verbal $)^{2}$
\end{abstract}

Em dezembro de 2018 aconteceu a primeira batalha oficial da Batista, no mesmo coreto do qual o entrevistado fala, e desde então ela vem ganhando frequentadores e se fortalecendo enquanto uma das maiores da cidade.

É importante notarmos o quão importante foi a divulgação "boca a boca" realizada em prol da batalha. A partir de uma publicação feita pelo citado MC Rasta, reconhecido na cena local enquanto um $\mathrm{MC}$ em ascensão, que já representou a região no duelo nacional de $\mathrm{MC}$, realizado em Belo Horizonte, a Batalha da Batista entrou no radar da "galera" de Belém e hoje é uma das que mais cresce na cidade.

A estrutura utilizada para a realização do evento é a mínima possível, utilizando apenas caixinhas de som portáteis, quando possível, e contando com os beats quando necessário. A assiduidade dos frequentadores demonstra, também, que esses detalhes não são tão importantes quanto a própria presença dos mesmos e a vontade de rimar.

A Batalha do Guamá ocorre também às sextas, a partir das 18h, na praça Benedito Monteiro, bairro do Guamá. Ocupa a porção da praça onde originalmente existia uma academia ao ar livre construída pela prefeitura no espaço, mas que hoje está completamente sucateada e caiu em desuso.

A praça Benedito Monteiro fica localizada na rua Barão de Igarapé Miri, no Bairro do Guamá. Fica em uma área próxima à feira do Guamá, umas das maiores feiras abertas da cidade, o que garante que seu entorno tenha uma dinâmica intensa pela manhã e reduzida à noite. Isso, no entanto, não significa que o espaço seja esvaziado quando anoitece, muito pelo contrário: o bairro continua vívido e com um grande número de pessoas nas ruas. Isso se deve, acreditamos, à grande concentração de lanchonetes, escolas, ambulantes e, nesse caso, à praça Benedito Monteiro.

Ali a "galera", que majoritariamente mora no bairro, pelo que pudemos perceber nas conversas que tivemos com os frequentadores do evento, se reúne nesse espaço por ser um dos poucos da praça que fica vazio.

A Batalha do Guamá foi uma das primeiras da cidade, motivo pelo qual ainda nos anos 2000 ela era uma das que mais atraia pessoas. Atualmente o número reduzido de participantes pode ser explicado a partir de alguns fatores inerentes ao próprio bairro, como explica um organizador:

aconteceu muita coisa aqui no bairro, teve a chacina no bar, e esse bar era aqui perto da praça onde a gente fazia a batalha, meio que ninguém ia pra lá porque ficava com medo. E tinham os bondes, porque o único bonde que passa lá, o Guamá, as pessoas têm que pegar o bonde e levar pro centro pras pessoas irem embora, eram dois bondes pra ir e dois pra voltar. (Informação verbal) ${ }^{3}$

As barreiras de acesso ao espaço, como podemos perceber, influenciam a Batalha do Guamá de forma incisiva através do poder que a violência e a criminalidade possuem sobre o imaginário criado no bairro e pela dependência que os participantes possuem do transporte público, que 
visivelmente não atende as demandas dessa porção do bairro de modo satisfatório. Esses problemas, no entanto, não prejudicavam a batalha a ponto de impedir sua realização.

Mesmo se dava pouca gente a gente se esforçava, mano, pra dar oito MC. A gente fazia com $8 \mathrm{MC}$ mesmo, mano, ia dando. A gente nunca fez com doze ou dezesseis, porque não tinha, a gente sempre fazia oito. Eu levava os beats, o Souza levava as caixinhas e a gente ficava na batalha. (Informação verbal) ${ }^{3}$

Aqui os participantes não contam com a presença da polícia no espaço da praça para garantir, mesmo que minimamente, sua segurança. Os MC ficam diretamente expostos aos riscos e já houveram casos em que isso resultou em violência e agressões.

Acho que da primeira vez que eu colei nessa batalha, eu batalhei, e nisso um moleque tava passando e levou uma facada porque um moleque tentou roubar ele. Do nosso lado, porque a gente tava lá na batalha. Quando foi na outra semana a batalha voltou e a gente continuou, mas mesmo assim, com a gente batalhando ainda continuava isso das pessoas tentarem roubar perto, mesmo que a gente ficasse lá pela batalha tinha gente que passava e tentava roubar a gente, mas mesmo assim a gente continuou. (Informação Verbal)³

A resistência ao ocupar o espaço, apesar das dificuldades apresentadas, faz com que a Batalha do Guamá seja considerada, na cena local, como um dos principais focos de luta do hip hop na cidade de Belém. Apesar de precisar fazer intervalos periódicos na sua realização por conta de episódios como o relatado acima, ela sempre retorna por conta da força de vontade de seus organizadores e frequentadores.

A Batalha do Triângulo acontece na praça do Triângulo, no bairro de Canudos, todas as sextas há cerca de quatro anos. Ela é fruto, como nos outros casos vistos aqui, da vontade que alguns MC iniciantes possuíam em ter uma batalha próxima de seu local de moradia, onde pudessem ficar até mais tarde sem se preocupar com o retorno para casa.

A praça, em seu entorno, conta com mercadinhos, açougues, um ponto de moto taxi e várias residências. Sem dúvida ela representa um ponto importante para o bairro, visto que é por lá que várias das linhas de ônibus que levam e trazem pessoas do centro da cidade circulam, é onde os transportes alternativos pegam passageiros e também faz parte do trajeto comum de quem precisa ir para São Brás a pé.

A criação desta batalha, em 2016, está diretamente relacionada com a experiência dos fundadores e a descoberta dos mesmos enquanto MC, como nos diz MC B., em entrevista.

Tipo, sempre rimava, desde pequeno e tal, sempre fazia uma rima, ficava na zoeira, tá ligado, mas eu não sabia o que era isso, entendeu, de rima, batalha, até que uma vez eu vi no YouTube e tal, umas rimas de uns caras lá de Brasília, e eu achei da hora, tipo "égua, isso que eu faço e tal, eu gosto de fazer isso, isso que eu faço". Aí nisso eu fui com meus colegas pra uma igreja, lá no Guamá, da 25, aí nós voltamos todos na resenha, lá da igreja, aí nós paramos lá na Praça do Triângulo, aí eu e meus colegas falamos "bora rimar, bora? Bora rimar aqui". (Informação verbal) 4

Podemos notar no relato acima que a espontaneidade foi decisiva para que a Batalha do Triângulo fosse fundada, advinda da vontade de rimar como lazer e fruto da resposta positiva que o local ofereceu à atividade. É interessante percebermos, também, que a escolha do local foi feita a partir do trajeto que os fundadores faziam cotidianamente. A praça, nos disse o mesmo MC, já era frequentada anteriormente por eles e sempre representou um ponto de encontro para bater papo, "trocar ideia", lanchar, namorar, etc. Um entroncamento no bairro que sempre atrai todo tipo de público. 
Não vou te mentir, tipo, não é mais como era antes, sabe? Tanto dos MC colarem quanto da organização. Antigamente era uns cinco, seis organizando. Aí hoje em dia ficou três, mas, tipo, só dois vai, eu e mais um. Aí tipo, de um mês para cá a batalha parou mesmo. Vamos ver se a gente volta em agosto. Porque também tem muita coisa pra gente fazer, estamos trampando com outras coisas. Estamos fazendo som, estamos estudando, estamos fazendo outras paradas. Aí é escroto, tá ligado? Sem apoio de nada fica ruim pra todo mundo. (Informação verbal) 4

Fica evidente que a maior complicação para que a Batalha do Triangulo continue com a mesma força que foi fundada é a falta de incentivos que superem as dificuldades cotidianas de seus organizadores. Percebemos, no entanto, durante nossa presença nas edições da batalha que ocorreram em 2018 e 2019, que os MC que frequentam a batalha se esforçam para que seja um evento divertido e sério.

Os participantes costumam dividir o espaço com moradores que também frequentam a praça e consumidores de comércios próximos, como lanchonetes e sorveterias do bairro. Não foram relatados ou presenciados atritos com outros grupos, mesmo com a proximidade que o tamanho reduzido da praça possui, mas, ao contrário, os olhares aqui se cruzam mais do que nas praças anteriormente apresentadas, possibilitando uma aproximação mais contundente entre batalha e curiosos.

\section{Espaço e lugar na realização das batalhas de rap}

À primeira vista uma constatação nos salta aos olhos: o hip hop não esconde, em momento algum, sua relação com o espaço. Muito pelo contrário, ele faz questão de deixar claro que essa relação nutre boa parte do seu existir, contida nos mais sutis comportamentos, como a mera presença no espaço, imprimindo sua existência na paisagem momentânea, e nas mais exaltadas manifestações, como quando, por exemplo, são realizadas atividades de intervenção, seja por meio de dança, "grafitagem" ou da música. Um primeiro exemplo disso é a apresentação das batalhas de rap em Belém: todas, sem exceção, são batizadas com referência ao local em que ocorrem. A referência ao espaço, além de representar uma forma de localização, carrega significados construídos por intermédio da existência desses indivíduos e das ações dos mesmos sobre a cidade, e não somente com relação ao espaço público em que reproduzem a cultura hip hop explicitamente, mas também com relação aos seus espaços de referência cotidiana, dos seus lugares, quebradas, setores, etc.

Fazendo referência aos primórdios do hip hop, nos Estados Unidos, onde essa cultura era moldada nas ruas e alimentada (fartamente) pelas várias injustiças a que eram submetidos os indivíduos que Ihe deram vida, aqui o processo não ocorre de forma diferente. Estabelecendo uma ligação direta que justifica a linguagem comum utilizada pelo movimento aqui ou lá, notamos que o bairro, a rua, o conjunto, ou quaisquer que sejam as referências ao espaço de moradia desses sujeitos ainda são a roda que move o hip hop. Tão complexas quanto as realidades desses sujeitos, portanto, será o movimento a que dão vida. Isso pode ser constatado quando, em qualquer evento referente ao hip hop e suas dimensões, sejam elas o rap, grafite ou break, as apresentações só são consideradas satisfatórias quando o nome de um indivíduo vem acompanhado do seu bairro de origem ou moradia.

Percebam: se cada um desses sujeitos carrega consigo o seu lugar de moradia, exaltam as características do seu bairro, positivas e negativas no que diz respeito ao senso comum sobre os mesmos, e se encontram completamente vinculados a essa ideia de representação que Ihes é 
atribuída pelos seus iguais, podemos pensar que eles levam seus lugares consigo para onde vão, não podendo se ver livres (não querendo, na verdade) de seus espaços de referência.

Leite (2004) utiliza o conceito de lugar para entender o espaço público, compreendido enquanto o espaço vivido e percebido de forma subjetiva, ligado ao cotidiano. "Uma demarcação física e/ou simbólica no espaço, cujos usos o qualificam e lhe atribuem sentidos diferenciados, orientando ações sociais e sendo por estas delimitado reflexivamente (LEITE, 2004, p. 284).

Aqui podemos notar um ponto chave para interpretarmos a presença desses jovens no espaço público. Antes de pensarmos o contato desse grupo com outros que também frequentam as praças precisamos pensar o contato entre eles. É no espaço público que o contato entre os sujeitos que constroem as batalhas vai evidenciar a complexidade dos mesmos. O hip hop não representa um grupo homogêneo, mas o conjunto de inquietações e desejos que nascem nos lugares de origem de seus sujeitos e se mesclam através do contato dos mesmos nos espaços que frequentam juntos. As praças, nesse contexto, adquirem o papel de espaço de síntese, uma espécie de palco que dá sentido à constelação de particularidades que juntos constroem a cena do hip hop de Belém.

Mas e quanto aos espaços públicos em si? Eles também são uma dimensão importante da cultura hip hop, sendo referenciados nos nomes das batalhas. Mas por quê? No caso da praça Floriano Peixoto não é difícil encontrar as respostas, conhecendo a importância que ela possui para o movimento, sendo considerada o solo sagrado do hip hop em Belém por ter sido onde os primeiros grupos de break ensaiaram seus passos ainda no século passado, mas e quanto às outras?

Para responder essa pergunta precisamos dar continuidade ao pensamento desenvolvido acima: se os sujeitos carregam consigo a complexidade de seus lugares, as representações do seu cotidiano, as demandas construídas com base nas particularidades dos seus "setores" e é no espaço público que essa constelação de particularidades ganha sentido perante o contato entre si, podemos dizer que o espaço público representa a coletividade que dá sentido ao movimento.

Durante uma edição da Batalha de São Brás realizada em outubro de 2018, na praça Floriano Peixoto, foram abertos espaços na programação da noite para a intervenção de artistas envolvidos com o movimento com o intuito de divulgar o "trampo" de MC e poetas/poetizas que compõem a cena. Nesses espaços pudemos ouvir as intervenções de pessoas que produzem o hip hop, mas de pontos de vista singulares, de lugares diferentes: versos que falavam sobre o racismo sofrido por pretas e pretos que carregam o peso da discriminação, do machismo que mata, do preconceito que segrega e aprisiona. Tudo com um teor cotidiano nas palavras, o que assegurava a legitimidade das palavras proferidas ali.

Em outra ocasião, na Batalha da Batista, realizada na praça Batista Campos em novembro do mesmo ano, durante conversas que antecederam o início do evento pudemos perceber como a linguagem do hip hop funciona como uma espécie de tradutor para jovens que, apesar de compartilharem características comuns, são diferentes. Brancos, pretos, homens, mulheres, jovens, adultos, moradores da periferia, do centro, da capital, do interior, etc. A diversidade era visível, de modo a destacar uma verdade muitas vezes negligenciada por aqueles que encaram o hip hop de fora: não se trata de um grupo homogêneo. Ali várias pessoas se reuniam não somente pelo gosto parecido, mas pela oportunidade que esse gosto oferecia para o diálogo.

Quando esses sujeitos se encontram, portanto, nas batalhas de rap, é como se seus lugares se encontrassem. Quando batalham, estão batalhando também os seus lugares e quando trocam experiências são seus lugares, na verdade, que estão interagindo.

Fica evidente para nós como o hip hop é, ao contrário do que alguns podem dizer, mais includente do que excludente, indo além do gosto musical ou estético para oferecer (ou servir como) um espaço de debate e encontro de diferenças. Nos dois exemplos acima pudemos perceber como 
vários sujeitos encontraram (assim como ajudaram a construir e são responsáveis por) um acolhimento na cultura hip hop, que por sua vez se manifesta majoritariamente no espaço público através das batalhas de rap.

Tomando como referência os relatos anteriores, podemos perceber a heterogeneidade desses sujeitos, a partir de suas construções identitárias e de suas relações com seus lugares, desde pautas ligadas ao racismo e ao machismo, no caso da Batalha de São Brás, até a percepção de recortes socioespaciais diversos na Batalha da Batista. Participantes que residem em áreas de periferia da capital, por exemplo, possuem demandas, discursos e desafios diferentes daqueles que residem em outras cidades da Região Metropolitana ou mesmo do interior do Estado. As violências que sofrem, direta ou indiretamente, os produtos que consomem, sua capacidade de acesso a determinados espaços ou mesmo o léxico que apropriam vão compor essas diferenças.

Nas batalhas essas diferenças ficam explicitas no uso de gírias, de palavras estrangeiras, na referência à programas de TV, músicas, regionalismos, construções de rimas sérias ou à leveza das mesmas. Se trata de um universo complexo de experiências que se entrelaçam.

Para exemplificar, julgo necessário relatar um sarau literário promovido pelos organizadores da Batalha de São Brás e realizado no auditório do Sesc Ver-o-Peso, importante centro cultural da cidade localizado próximo a pontos turísticos como o Ver-o-Peso e Estação das Docas. O evento em questão, de nome "Sarau Tem que Ser Sagaz", reunia MC da cidade, poetas e poetisas envolvidos com o movimento com o intuito de compartilharem suas produções, música e poesia, e discutirem temas interessantes ao movimento, como racismo, machismo, homofobia e outros que surgiram com o decorrer do evento. O que gostaria de destacar, que é relevante para nossa discussão, é o fato de que todos que subiam ao palco, independente de gênero, idade ou cor, eram imediatamente referenciados pelos apresentadores com relação aos seus bairros. Eles estavam ali não somente representando a si próprios, mas também seus lugares, seus "setores", "quebradas", "pedaços".

A escolha do espaço público, para o hip hop, está pautada em dois pontos principais: a relação que o movimento possui com a cidade e a questão do acesso aos espaços, que acaba por limitar o alcance do hip hop a determinados locais que compõem a malha urbana.

A relação que o movimento possui com a cidade está diretamente relacionada com a própria relação que os sujeitos possuem com seus lugares. Em nossa presença em campo e conversas com integrantes do movimento percebemos que isso se manifesta em duas vias principais.

Primeiramente por meio da história do hip hop na cidade, como contextualizamos anteriormente por meio de Silva (2009) e Borda (2016), que foi caracterizado por um processo de reflexão sobre a realidade socioespacial em seus lugares e a potencialidade de suas ações dentro do hip hop. É interessante notarmos como a construção do movimento não se furta de historicidade, seja por meio do regate de uma narrativa oral, dos veteranos, seja por meio de construções estilísticas no próprio seio identitário.

A outra manifestação da relação entre o movimento e a cidade se expressa por meio da relação entre os sujeitos e seus lugares. Cada participante que chega a uma batalha de rimas carrega consigo uma relação intima com seu lugar. Isso pode ser expresso na forma de falar, no meio de locomoção, nos subgrupos que integra e mesmo na própria apresentação ou construção de apelidos. Em nossa presença em campo ficou evidente a importância da identificação dos MC com seus bairros, ruas, vilas (setor, quebrada, pedaço), por estes serem parte de suas identidades. As demandas que carregam e os discursos que proferem estão intimamente ligados aos seus lugares, daí nascem os pontos de diferenciação e de aproximação com outros membros do movimento ou mesmo com indivíduos que não compõem este último. 
Quanto ao acesso, durante nossas conversas com participantes das batalhas, quando indagamos o motivo pela escolha da praça para a realização dos eventos, a resposta parecia sempre simples: "acho que porque são locais de fácil acesso" (Informação verbal) ${ }^{4}$. De fato, a simplicidade da escolha se pauta na complexidade das razões. A tendência de privatização dos espaços vem acompanhado da monetização do acesso aos mesmos (SERPA, 2007), tal barreira limita consideravelmente as possibilidades de lazer desses jovens, que perante a necessidade de um espaço de encontro se dirigem às praças da cidade. Não podemos ignorar o fato de que a flexibilidade de usos que esses espaços oferecem também é importante por permitir a heterogeneidade necessária aos grupos fazem uso deles.

Se é através do encontro dessas diferenças que o hip hop vai extrair sua riqueza é o espaço público que torna isso possível ao atender alguns requisitos básicos, como espaço físico adequado para comportar o número de pessoas que participa dos eventos de forma gratuita e com a flexibilidade de uso que permite que as atividades, como as batalhas de rap, sejam realizadas. Esse motivo está diretamente relacionado com o segundo, que diz respeito ao acesso dos sujeitos ao espaço e a sua liberdade para realizar suas atividades.

Os lugares, para Leite, não existem por si só. Mesmo que se conformem através de subjetividades comuns a determinados grupos, só mantém sua singularidade identitária através da contraposição a outros grupos, outros lugares (LEITE, 2004, p. 307).

Em casos como o da Batalha de São Brás, Batalha do Triângulo e Batalha do Guamá, por exemplo, cada grupo ocupa seu espaço, sem necessariamente estabelecerem uma forma de diálogo explicito e direto dentre si. Cada um se preocupa com seus objetivos ali e desenvolve suas atividades de forma independente.

$\mathrm{Na}$ Batalha da Batista, no entanto, pudemos perceber que os grupos mantêm um contato mais explícito em alguns momentos, de modo a se ligarem de forma mais direta. Em diversas ocasiões, por exemplo, grupos de igrejas evangélicas pediram para entrar na roda e divulgarem suas palavras, em alguns momentos até fizeram orações nas batalhas e distribuíram panfletos. Em outros momentos alguns grupos musicais que se reuniam nos coretos das praças pediram para que a batalha se juntasse a eles. Em todas essas ocasiões os integrantes da batalha sempre se mostraram extremamente receptivos e educados, as vezes aceitando tais convites e as vezes declinando, mas sempre oferecendo espaço para qualquer um se pronunciar.

Em ambos os casos apresentados acima, podemos identificar a presença de diferenças sendo explicitadas no espaço público. Tanto quando há contato direto ou quando não há, essas diferenças são reconhecidas e culminam no reconhecimento da polissemia da qual nos fala Leite (2004). A heterogeneidade desses usos da praça se traduz na criação de um espaço plural e que abarca a complexidade daqueles que dele fazem uso, dos seus lugares.

Para Georg Simmel (1986) esse encontro dos lugares só é possível caso o espaço não seja objeto de disputa. O autor defende que tal coexistência entre os grupos seria possível somente em espaços que existam "entre lugares", visto que cada grupo possui seu espaço de referência próprio, que não abarca outros grupos: seu próprio lugar (SIMMEL, 1986, p. 646). "Os lugares precisam de um espaço social que os transcenda e os questione" (LEITE, 2004, p. 311).

\section{Considerações finais}

Neste artigo tivemos o intuito de compreender a importância dos lugares de referência dos sujeitos que fazem parte do movimento hip hop em Belém, Pará, no contexto da realização de batalhas de MC em espaços públicos da cidade. 
Pudemos, através da discussão dos conceitos de lugar e espaço público, perceber que as diferenças criadas a partir dos sentidos atribuídos por esses sujeitos são afirmadas e reafirmadas pelo contato com outros grupos que também carregam consigo os seus lugares, contato esse que será possível somente em espaços que o permitam.

Concordamos com Leite (2004) e Serpa (2007) quando dizem que o espaço público seria o espaço adequado para esse tipo de interação, por não configurar, necessariamente, um espaço de disputas, mas sim um espaço que permita o encontro das diferenças.

As batalhas de rap realizadas na cidade contribuem para esse encontro de diferenças tanto por polarizarem jovens advindos de várias periferias da cidade quanto por acontecerem em espaços públicos, locais que permitem esse contato e o diálogo dentre eles. A explicitação dessa miríade de intersubjetividades é expressa nas demandas trazidas nos discursos incorporados pelos sujeitos e representam uma voz que surge nos lugares e se encontram para realizar o processo de ver e ser visto, retroalimentando-se em uma ação política que extrapola seus limites e fortalece suas existências.

A importância dessas manifestações do/no espaço, em termos práticos, se encontra no fortalecimento de um movimento reivindicatório que extrai da complexidade espacial a sua força, incorporando lutas diversas que são comunicadas e amadurecidas no interior do movimento hip hop. Este é um ponto. Outro ponto que julgamos importantíssimo é o fato de que essa prática permite que outros grupos da cidade, com suas próprias particularidades, também dialoguem no espaço público, expandido a extensão deste fazer político para além do hip hop.

\section{Notas}

1 S. M. J. (Nome ocultado para preservar a entrevistada), MC e ativista do movimento. Entrevista concedida ao autor. Belém, 2017.

${ }^{2}$ V. F. (Nome ocultado para preservar o entrevistado), MC. Entrevista concedida ao autor. Belém, 2019.

${ }^{3}$ MC D2 (Nome ocultado para preservar o entrevistado). Entrevista concedida ao autor. Belém, 2019.

${ }^{4}$ MC B. (Nome ocultado para preservar o entrevistado), organizador da batalha do Triângulo. Entrevista concedida ao autor. Belém, 2019. 


\section{Referências}

BORDA, B. G. S. (2016). Vivências, tecnologia, ritmo e etnografia: uma visão afroamazônica sobre o rap nacional. 2016, 136 f. Tese (Doutorado em Ciências Sociais) Programa de Pós-Graduação em Ciências Sociais - Antropologia, Universidade Federal do Pará, 2016.

COSGROVE, D. (1998). A geografia está em toda parte: cultura e simbolismo nas paisagens humanas. In: CORREA, R. L; ROZENDHAL, Z. Paisagem, tempo e cultura. Rio de Janeiro: EDUERJ. P. 92 - 122.

CRESWELL, J. W. (2007). Projeto de Pesquisa: métodos qualitativo, quantitativo e misto. $2^{\text {a }}$ ed. Porto Alegre: Artmed.

GOLD, R. L. (1958). Roles in sociological field observations. Social Forces, v. 36, n. 3. Oxford, p. 217223.

GOMES, P. C. C. (2014). Espaços Públicos: um modo de ser do espaço, um modo de ser no espaço. In: CASTRO, I. E.; GOMES, P. C. C.; CORRÊA, R. L. (orgs.). Olhares geográficos: modos de ser e viver o espaço. Rio de Janeiro: Bertrand Brasil, p. 19-41.

LEITE, R. P. (2004). Contra-usos da cidade: lugares e espaço público na experiência urbana contemporânea. Campinas: Editora da Unicamp.

MAGNANI, J. G. C. (2002). De perto e de dentro: notas para uma etnografia urbana. Revista Brasileira de Ciências Sociais, São Paulo, v. 17, n.49. Disponível em: https://www.scielo.br/pdf/rbcsoc/v17n49/a02v1749.pdf. Acessado em: 22 fev. 2019.

MASSEY, D. (1994). Space, Place, and Gender. Minneapolis: University of Minnesota Press.

NETO, N. T. (2008) Multiplas trajetórias juvenis em Guarapuava: Territórios e redes de sociabilidade. 2008. 532f. Tese (Doutorado em Geografia) - Programa de Pós-Graduação em Geografia, Universidade Estadual Paulista, Presidente Prudente.

SERPA, Â. (2007). O Espaço Público na Cidade Contemporânea. São Paulo: Contexto.

SILVA, E. C. (2009) Territórios Urbanos: O movimento Hip hop e a Dinâmica da Cidade de Belém, Pará. Papers do NAEA, n. 228. Belém: NAEA.

SIMMEL, G. (1986). Sociologia, 2: estúdios sobre las formas de socialización. Madri: Alianza Universidad.

SOUZA, M. L. (2013). Os conceitos Fundamentais da Pesquisa Socio-espacial. Rio de Janeiro: Bertrand Brasil.

VELHO, G. (1980). O antropólogo pesquisando em sua cidade: sobre conhecimento e heresia. In: VELHO, G. (orgs). O Desafio da Cidade: novas perspectivas da antropologia brasileira. Rio de Janeiro: Campus. 